\title{
Integrated Framing: A Micro to Macro Case for The Landscape
}

\author{
*Filip Aggestam \\ Department of Environmental Engineering, University of Natural Resources and Life sciences, Austria
}

Submission: February 22, 2017; Published: March 21, 2017

*Corresponding author: Filip Aggestam, Department of Environmental Engineering, University of Natural Resources and Life sciences, Vienna, Austria, Email: filip.aggestam@boku.ac.at

\begin{abstract}
This paper takes an integrated approach to framing, utilising the landscape concept to explore vertical and horizontal relationships between frames. It is based on three previously published articles as case studies. The first reviews wetland restoration and how we frame landscapes, the second explores how institutions have operationalized stakeholder participation in the landscape, and the third investigates how science and policy has framed the ecosystem concept in relation to the landscape. The innovative aspect has been to link the macro level (e.g. value frames in policy) to framing effects at the meso level (e.g. institutions affecting policy implementation) and micro level (e.g. individual frames affecting wetland restoration). The main argument put forward is that a multi-level synthesis of framing requires that we integrate different theoretical perspectives on frame theory.
\end{abstract}

Keywords: Frame theory; Framing; Landscape management; Integrated research

\section{Introduction}

Our landscape, whether natural or managed, is an interface through which society interacts with nature. Examples of this are economic activities, such agriculture and forestry, and societal priorities, such as public health and conservation. The concept of a landscape consequently connects people (directly or indirectly) with nature and vice versa Norton [1]. The landscape can be seen as a product of nature that is intertwined with human value-systems that are inherently bound up with the landscape, the priorities we set as a society, and policy making Eder [2], Harrison \& Davis [3]. This relationship presents a physical manifestation of historical and present day human values Fischer \& Marshall [4]. One illustrative example of human-landscape interactions comes from the conservation movement and questions about the best way to manage nature. For instance, contrasting interests from different groups (e.g. climate change activists and industrial lobbyists) present arguments that are consistent with different socio-economic, cultural and professional perspectives Soini \& Aakkula [5]. These differences generate conflicts in (or about) the landscape that are ultimately based on how nature should be framed and utilised.

Frames are in this case the conceptual structures that individuals (or institutions) use to perceive and organise how to think and communicate about the landscape Fischer \& Marshall [4] Howley, Donoghue, \& Hynes [6], a process that has been addressed by many disciplines. One of these views frames as an interpretive lens, a cognitive device, which filters how people perceive and give meaning to items, events and experiences. This research stream originates from Minsky's cognitive frame theory [7] and often refers to unconscious structures called "schemas" Lakoff [8]. Another discipline subscribes to the view of frames as a socially constructed communication device used to conceptualise and convey a specific narrative (e.g. to promote a certain interpretation). This strand of research originates from Bateson's interactional framing research [9], and is often found in media communication research e.g. Entman [10], Goodman [11]. The key distinction here is that cognitive frames are rooted in the individual mind, either biologically or through learning, while interactional frames are located in the interaction and social construction of meaning Donahue [12], Rein \& Schon [13].

In both instances, the idea behind frame theory is basically that one issue can be viewed from multiple perspectives. This means that framing implies how a person conceptualises said issue, which is dependent on factors such as values, attitudes and how the issue is conveyed. When applied to the landscape, this implies that people's attitudes towards a landscape vary along with their framing. For instance, findings by Chong and Druckman [14] indicate that individuals with strong values are affected less by frames that contradict those values. Another author, Nelson et al. [15], argue that frames represent the bridge between elite 
discourse about an issue and how the public understands that issue, which is connected to how information is communicated - essentially seeing frames as devices that communicate human intent. Taken together this means that people with opposing values would be less successful in persuading each other. This basic argument is mentioned to show the explanatory utility of framing as an analytical approach and to argue that framing provides a holistic approach to investigate the human-landscape interface Fischer \& Marshall [4], Howley et al. [6].

The background for this article resides in three previously published case study articles. These cases are not geographically related but they explore framing effects at different levels of implementation, from communication (involving single individuals) to policy-making (involving institutional actors). The first case reviews wetland restoration and how it is influenced by landscape frames. The second case looks at how individuals and institutions have operationalized stakeholder participation and how framing has influenced participatory processes in the landscape, and the third case explores how scientific literature and policy documents have framed the ecosystem concept over time. Case studies like these are usually analysed separately from each other (which has already been done) but the novel approach taken here is to examine framing effects not only at an individual (micro) level but also at an institutional and policy (meso and macro) level. This vertical multi-level approach characterizes one key reason as to why the landscape concept has been chosen as a "frame within the frame". More specifically, the landscape concept allows this paper to contextualise the case study articles and to link these back to a wider body of research on framing.

The multitude of conceptual approaches to framing research further highlights that there are many definitions and applications of frames Cornelissen \& Werner [16]. It is for this reason that the main challenge taken up by this paper is to use the landscape concept to present an analytical approach that allows for an integrated take on framing. By exploring vertical and horizontal relationships between frames, the intent is to investigate how frames are linked to the real world and our impact therein. The challenge, therefore, is to disentangle how frames are embedded at different levels, and to integrate these perspectives, taking different disciplinary approaches into account.

\section{Bridging the Theoretical Divide}

Numerous research strands on framing can be found in the literature, ranging from media and communication Druckman [17], Hanggli \& Kriesi [18], policy e.g. Daviter [19], Van Buuren, Vink \& Warner [20] and psychology Kahneman \& Tversky [21]. While it is beyond the scope of this article to provide a detailed review of all relevant research areas, an integrated approach also requires that distinctive areas of research are considered, and that the connection between frames at different levels of analysis - from the micro to the macro level - are taken into account Cornelissen \& Werner [16]. The purpose of this section is thus to provide an introduction into framing at the proposed levels of operationalization.

Framing research, at the micro level, most often focus on cognitive theories where frames, or "schemas", correspond to cognitive structures (e.g. preferences and values) that are shaped by mental functions Kahneman \& Tversky [21] and personal experiences Shen \& Edwards [22]. Focusing on the individual, this can be everything from how a person interprets a landscape, makes social judgements and is able to be reflective. The main idea is that cognitive frames are not static but stable "meaningmaking systems" based on cognitive structures that affect how we learn and retain knowledge as well as how we interpret new information in a cumulative manner Nelson [15]. The application of a cognitive frame is comparable to evaluation processes found in simple heuristics Gigerenzer \& Todd [23] This process is subject to how our brain reacts to external stimuli, which dictates how we behave, with, for example, emotionally charged words affecting how we make decisions Devignemont \& Singer [24], Lakoff [8]. The main distinction between the micro, meso and macro level is found in the emphasis on individual cognition.

The meso (or organisational) level is often characterised as collectively constructed sets of assumptions, knowledge and/ or value systems (e.g. in communities or social groups). In the literature, this is frequently found in social movement or political action research, such as frames that are strategically used to persuade or gain support from the public Hanggli \& Kriesi [18]. This equates to what Snow et al. [25] call a frame alignment process, namely, when a specific frame prompts individuals to undergo a frame transformation (or re-framing). For example, at this level, strategic messages (e.g. socially constructed realities) make people look at things differently, and, if successful, change their opinion or behaviour ( Jerneck \& Olsson [26]. This can also refer to organisational frame constellations, such as technological or strategic frames, that dictate how an organisation projects its perspectives (e.g. value frames) onto its staff or to a wider audience using, for example, rhetorical devices Schmidt [27]. Framing is on this level most often seen as an interactional (or socially constructed) meaning-making process.

The macro (or institutional) level is most often portrayed through neo-institutional theory, in terms of the creation of new markets, shared conceptions, or the diffusion of new ideas and practices (e.g. cultural framing). This process influence social meaning-making, stabilises power arrangements and affect interactional patterns Bateson [9], Goffman [28]. The strength of the framing concept at the institutional level is that it refers to, on the one hand, a macro framework that allows individual frames to interact under one umbrella (e.g. shared values), and, on the other hand, as a temporally stable frame that allows researchers to infer how institutions (as well as individuals) perceive or value a landscape Benford \& Snow [29]. It may also provide insights into how organisations will behave. For example, 
the process of conventionalising a new approach to landscape management may go from being perceived as something negative to becoming cognitively embedded and accepted by the wider public. This process would entail that it first emerges as a new topic, becoming established as an institutional frame, and then generates a shift in understanding. This is, of course, a generalisation, but it illustrates that the macro perspective provides us with a final link in the framing process, allowing us to define structures of meaning that shape how we collectively interact and understand reality.

The next section will review how these levels connect with the landscape concept. More extensive reviews of frame theory can be found in Coninx et al. [30], Cornelissen and Werner [16], Van Hulst and Yanow [31] Chong \& Druckman [14], among others. It should further be noted that an integrated approach to framing research is not a novel suggestion Dewulf et al. [32], Donahue [12]. In a recent special issue on framing politics it was argued that framing is in need of an integrated research approach Matthes [33]. The notion of integrated framing research presented in the special issue is different from the one taken here. Matthes argues that framing research needs to move beyond single case studies to link findings across cases in larger integrated projects. It is suggested that we should pursue integrated models of framing Matthes [13] and to look at the entire framing process (micro to macro), not only segments De Vreese [34]. This work follows the same argumentation but argues that linking levels of frames (or steps in the framing process) to larger models on framing is only part of an integrated approach. Another aspect that needs to be addressed is theoretical limitations (or tunnel vision). This implies that research on frames is often blinded by divergent theoretical approaches behind the framing concept, which must be addressed as part of an integrated approach. Integrated framing research can for the purposes of this paper be described as a blend between Dewulf et al. [32] "meta-paradigmatic perspective" that delineate and mix approaches to framing with varied ontological and epistemological backgrounds to Matthes [33] call for an integrated model.

\section{Framing the landscape - a micro to macro perspective}

Landscapes, as a canvas for individual, collective and institutional frames, provide an appropriate functional boundary for exploring framing effects from a micro to macro level. More specifically, the landscape is a physical environment in which people, institutions and policy interact, both horizontally and vertically. The landscape can be seen as a human product framed within a constructed set of values - that provides an opportunity to investigate how frames are operationalized in practice Kaltenborn \& Bjerke [35]. This is especially important since different individuals live in, interact with, and ascribe meaning to the same landscape, assigning multiple interpretations Howley et al. [6], Soini \& Aakkula [5]. These varying perspectives provide the contextual background for this paper. The landscape is however only applied as a conceptual framework and other concepts (e.g. water and climate change) could also be applied.

On a micro (or individual) level, our attitudes towards the landscape would be dependent on a subset of issues (e.g. motivation and knowledge) that make an individual assign different importance to various attributes of the landscape Fischer \& Marshall [4]. For example, on evaluating the pros and cons of landscape conservation, one may believe that it will favour biodiversity but harm the economy. These attributes would be valued differently depending on whether the landscape is seen as a place for recreation, as a source of income or whether it is an area in which one grew up or is merely visiting Buijs and Elands [36]. The framing process would consequently be dependent on the individual's cognitive representation of the landscape and the application of cognitive structures (or mental models) to facilitate and filter information Gigerenzer \& Todd [23], Kaufman \& Gray [37]. These factors would determine what attributes of a landscape a person favours Meso and macro level frames influence how an individual interprets experiences, facts and events within a landscape Stern [38]. For example, a moderator (e.g. a negotiator or organisation) may attempt to elicit certain frames that favour a specific outcome, such as the mobilisation of people to support landscape conservation Dewulf [32], Snow et al. [25]. Some practical examples would be framing during stakeholder participation Fuller [39] how landscape preferences are articulated Buijs [36] and affiliations to social movements Benford \& Snow [29]. These social and contextual aspects of framing would interact with cognitive frames and affect how we make sense of and interact with people. Ultimately, these frames affect how we (as individual or groups) make decisions about the landscape.

It should finally be noted that the link between a frame and effects on the landscape is not always easy to discern. Meso and macro level frames propagated through media Goodman [11], policy Schon \& Rein [40] and cultural factors Buijs [36] have been characterised in their respective research areas, but it is nearly impossible to quantify their impact on a landscape. That being said, understanding the link between the macro (e.g. policy making) and the micro level (e.g. individual actors) is more important in the current socio-economic and political climate. For example, in recent years we have seen a decentralisation of power in Europe van der Windt [41], including a shift from traditional top-down to participatory decision-making processes, where individual and collective actors are invited to express their views during landscape planning Fuller [39]. These developments highlight the need for a vertical (multi-level) approach that can investigate framing effects at the micro, meso and macro level as well as how they interact with the landscape.

\section{Analytical Approach}

The review demonstrates that frame theory could fall into two large formative strands, namely, stable meaning-making 
systems (e.g. cognitive and institutional frames) and socially generated meaning-making (e.g. temporally constructed frames), including a range of interactions and variations at different levels Cornelissen \& Werner [16]. However, to allow for an integrated approach, it is suggested that the framing process and associated research areas be distinguished into three functional categories cognitive, contextual and purposedriven framing. These categories are seen as meta-frames that integrate different theoretical strands to depict the framing process (Figure 1).There are two main steps associated with the analytical approach.

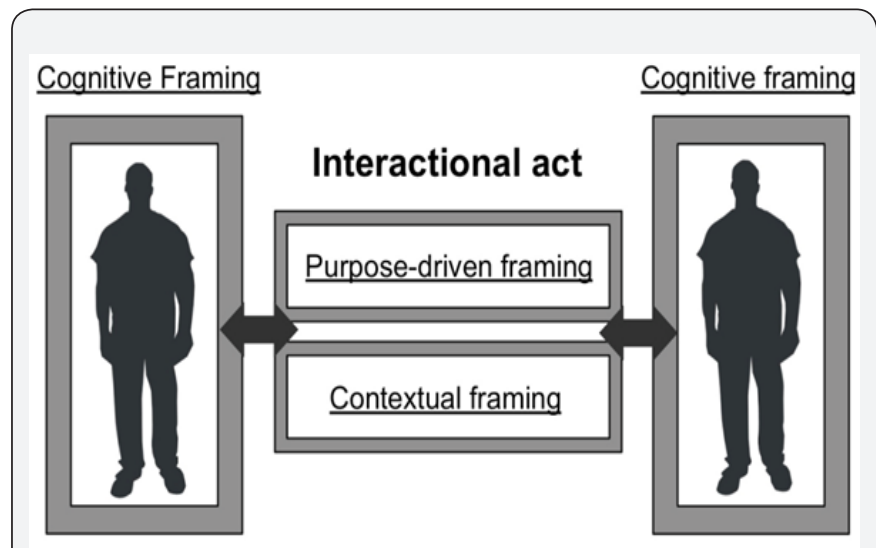

Figure 1: Framing in action - contextually and temporally defined.

\section{Characterising the Framing Event}

The first step requires that the comparable elements between (and across) the case studies are described. This will be achieved by defining each case as a separate interaction and applying the same conceptual structure (Figure 1). In this case, an interaction simply refers to the analysis, transfer or exchange of information, whether intentional or unintentional, through body language, verbal and written communication. The background for each case (what and where), the interactional act (the how) and framing effects (impacts) will be presented and consideration will be given to effects on the landscape (whether direct or indirect) at each level. It should be emphasised that purpose here is to demonstrate the analytical approach and that the level of detail for each case (principally due to space limitations) is restricted. The reader is referred to the publication associated with each case for more information on the results and methodologies applied.

\section{Breaking down the framing process}

The second step relates to how framing is defined and how it is applied across the cases. This means breaking down the framing process into functional categories. The first of these concerns our cognition (how individuals or groups evaluate information), the second is the context in which people find themselves (e.g. at a political rally or reading an advertisement), and the third is the underlying purpose (e.g. the specific intent of the framing process). These are described in more detail below:

\section{Cognitive framing}

Human cognition, at a micro level, help individuals make sense of a physical and social environment during an interactional act (Figure 1). In practical terms, this means that our brain evaluates external information (e.g. media content), which, depending on the content, activates certain parts of our brain (e.g. generating an emotional response) that subsequently influence how we behave Gross \& D Ambrosio [42] Hanggli \& Kriesi [18]. At the meso to macro level, cognitive framing would, in these terms, consist of collective (or institutional) frames affecting this process George [43]. The emphasis is on our brain as an information processor and its effect on behaviour. For instance, we often search, interpret and recollect information in a way that confirms our own beliefs Nickerson [44]. Biases that make it difficult to consider the framing process without reflecting on some inherent cognitive structures that affect interactions at any level.

\section{Contextual framing}

The framing process is also part of a temporally defined interaction. Contextual framing is, for this reason, significantly interlinked with cognitive framing, as together they set the stage for how people communicate. The distinction here is that the interactional act is defined entirely by temporal and contextual factors e.g. social cues, power relations and the setting that shape the framing process Entman [10]. Both contextual and cognitive framing is part of the same complex social process that makes up an interaction and how we chose to communicate and portray ourselves to our external environment in line with constructivist arguments. It is argued that social constructivists are correct to a certain extent, however, cognitive framing (whether innate or acquired) interacts with how a dialogue is collaboratively generated Eder [2]. Contextual framing is as such specific to each interactional act, time-specific, and characterised by the physical and social setting in which the interaction takes place.

\section{Purpose-driven framing}

The framing process is also characterised by the underlying intent. This means that each framing process is subject to a specific purpose. Examples of this would be media attempting to shape opinion Goodman [11], negotiators attempting to resolve conflicts Dewulf et al. [32] and policy documents attempting to promote the uptake of a collectively negotiated frame Jacoby [45]. These activities employ cognitive and contextual framing to various degrees and purposes; they are distinguished by the intentional manipulation of the frame creation process that they also require, such as the seeking of a specific framing effect. Purpose-driven framing is thus the intent (whether conscious or not) that underlies the framing process and feeds into and shapes the interactional act such as manipulating the type of information provided Gross [46] or influencing power dynamics Entman [10] during issue framing.

These functional categories demonstrate how different theoretical approaches (with varying ontological and 
epistemological backgrounds) can provide a more comprehensive picture of the framing process. More importantly, dividing the framing process into three functional categories allows for an integrated approach. To demonstrate how this can work in

Table 1: Functional categories applied to break down a framing process.

\begin{tabular}{|c|c|c|c|}
\hline Case Example & Cognitive Framing & Contextual Framing & Purpose-driven Framing \\
\hline $\begin{array}{c}\text { Imagine an external consultant } \\
\text { attempting to facilitate the uptake } \\
\text { of a new management approach in a } \\
\text { company... }\end{array}$ & $\begin{array}{c}\text { Current power hierarchy } \\
\text { suggests that... }\end{array}$ & $\begin{array}{c}\text { To reduce impact from power } \\
\text { dynamics... }\end{array}$ & $\begin{array}{c}\text { Informational content (or frame- } \\
\text { building) is designed to... }\end{array}$ \\
\hline & $\begin{array}{c}\text { Subordinate individuals are less } \\
\text { expressive when their superiors } \\
\text { are present. } \\
\text { Institutional norms are not } \\
\text { conducive to new perspectives. }\end{array}$ & $\begin{array}{c}\text { Superiors are not included in } \\
\text { the training workshop. }\end{array}$ & $\begin{array}{c}\text { Reflect the values of the } \\
\text { organisation and its employees. }\end{array}$ \\
\hline & $\begin{array}{c}\text { Participatory format (e.g., } \\
\text { roundtable) is chosen for a } \\
\text { more inclusive approach. }\end{array}$ & $\begin{array}{c}\text { Evoke dialogue and support the use } \\
\text { of positively framed statements. }\end{array}$ \\
\hline
\end{tabular}

\section{Case Studies}

\section{Micro case - Restoring Wetlands in an Agricultural Landscape}

This article focus on two wetland restoration programmes covering two catchment areas, Kavlinge River and Hoje River, in southern Sweden. The Kavlinge programme was launched in 1995 and the Hoje programme in 1991, with the aim of reducing nutrient runoff into the Baltic Sea. Restoring, rehabilitating or constructing new wetlands, ponds or riparian zones to reduce the inflow of nutrients into rivers and lakes in the respective catchment areas helped to achieve this objective. The metaobjective of the programmes was to reduce nutrient runoff from the agricultural landscape for more details).

\section{i. Background}

The focus in this case is on the interaction between individual frames. Participation in the wetland restoration process was voluntary; this makes the programmes dependent on the willingness of individuals to provide land and a context in which the landowners were more powerful in comparison with other stakeholder groups (e.g. researchers and NGOs). This generated a power imbalance between stakeholder groups that made it possible to make inferences about the impact individual frames had on the restoration process, demonstrating a direct and quantifiable framing effect on the landscape.

\section{ii. Interactional Act}

The programmes relied on a single negotiator to persuade landowners to participate. This was identified as the single most important interaction, corresponding to an interactional act between individual frames at the micro-level. The impact from negotiations between landowners and the programmes was frames associated with wetland framing became a key practice, (Table 1) breaks down a fictional example of power relationships affecting the uptake of a new project management system (Table 1). determinant for how wetlands were restored. For instance, most landowners were influenced by prevailingly negative views on wetlands in the landscape (e.g. raising the water table), professional interests (e.g. effects on income), negative experiences with the municipality and the public (e.g. property damage) as well as a lack of knowledge.

\section{iii. Framing Effects}

The landowners' position of power allowed them to impose individual (purpose-driven) frames that restricted the operational space for the programmes. This allowed the landowners to have a direct impact on the appearance of the wetlands and, by extension, the landscape. The purpose-driven framing generated framing effects in the form of structural adjustments (e.g. reduced inflow of water), which lowered the wetlands ability to retain nutrients and consequently lowered its environmental impact. This framing process was in turn significantly interlinked with cognitive value-based differences. In this case, three types of principal value orientations affected the framing process. These were anthropocentric frames (ranging from weak anthropocentrism to environmental pragmatism), "nature-centred" ecocentric frames and multi-value frames (corresponding to a mix between ecological, social and economic values) interacting with the landscape. On an individual level, this is more easily understood as a spectrum of anthropocentric to ecocentric perspectives. Across this spectrum, individuals differ in how they perceive the landscape and in the importance and functions associated with both wetlands and the agricultural landscape. It basically became a question of how values affect land use. For example, the landowners' negative perspective toward the wetlands was often linked to agricultural productivity, making it an anthropocentric perspective that influenced the restoration process. This demonstrates how individual frames provided different motives for decision making and how they 
were forced on the landscape due to the operational conditions of the programmes.

\section{Meso case -Engaging Stakeholders in Environmental Projects}

This article reviewed nine projects implemented by the United Nations Development Programme (UNDP), the International Commission for the Protection of the Danube River (ICPDR), and the International Institute for Applied Systems Analysis (IIASA). These projects were grouped into three case studies depending on the organization implementing the project. All cases were at the forefront of stakeholder participation, taking a leading position on stakeholder participation. The main objective of this study was to analyse how project managers frame stakeholder participation; however, the emphasis in this paper is on the effects of institutional frames for more details).

\section{i. Background}

The focus in this case is on institutional (meso level) framing as it allows for inferences on how stakeholder participation was framed in practice. The article investigated how individual frames (project managers) and institutional frames (international organisations) affect the operationalization of stakeholder participation and the incorporation of collective frames (as represented by stakeholder groups) in projects that are implemented in the landscape. The link to the landscape is indirect, as the impact of institutional frames cannot be quantified however all projects had environmental targets that affected the landscape.

\section{ii. Interactional Act}

This case is characterised by two forms of interactions. One between project managers and the organisation they worked for (making up the institutional frame) and one between the organisation (project managers and consultants) and stakeholder groups (representing collective frames). These internal and external interactions (from an organisational perspective) demonstrate how institutional frames can shape how project implementation. It also demonstrates the difficulties in incorporating new value orientations, both at an institutional level (e.g. participation as a new management tool) and in terms of collective frames (e.g. stakeholders' alternative value orientations).

\section{iii. Framing Effects}

Costs or benefits (actual or perceived) linked to control or resource issues affected how institutional and individual frames shaped stakeholder participation. One key finding was that managers were often forced to incorporate stakeholder participation in order to obtain funding, but the organisation did not strictly control how participation was implemented. This is in line with an isomorphic response as defined by George et al. [43]. More specifically, institutions choose an action consistent with other actors in order to achieve legitimacy. Nonetheless, the discrepancy between the actions of the organisation and the manager highlights a core framing effect, namely, that the institution conformed to normative expectations by engaging stakeholders but did not enforce the new practice. This meant that project implementation did not depart from the institutional frames conformed by its employees. In most cases, this resulted in that stakeholder participation was relegated to the sidelines. This implies that organisations facing legitimacy related changes to their operating environment are forced to adapt so that they do not lose funding, although it does not mean that institutions change the established way of doing things, particularly, if the risk of doing so (e.g. loss of power) outweighs the benefits of sticking to business-as-usual. Institutional frames were consequently more important than the policy instrument and should be separated from the organisation in term of its impact on policy implementation. It demonstrates the balance between the importance attached to a policy and the values attached to it by the organisation. Only if sufficient priority is given to a policy can a change in organisational behaviour be seen. The implication for the landscape is twofold. At a meso level, institutional frames affect how policies are implemented in the landscape and, at the micro level, individual frames imposed by managers affect operational conditions (e.g. setting targets for the landscape).

\section{Macro case - Defining the Ecosystem Concept in Science and Policy}

This article consist of a longitudinal analysis of scientific literature and policy documents, starting from when Arthur Tansley introduced the ecosystem concept in 1935 Tansley [47]. Scientific literature and policy documents were analysed to develop a frame typology and to characterize value frames that determine how ecosystems are perceived. The documents analysed are seen as products of a social and dynamic process through which negotiated and/or dominant frames are expressed at a macro level, over time. This case has only indirect implications for how the landscape is managed, such as reflecting how, as groups or organisations, we value landscapes.

\section{i. Background}

The focus in this case is on value frames that drive science and policy-making. The ecosystem concept is used to define how the concept itself is being framed and illustrates its transformation from a scientific term to a normative concept in both science and policy. Given the type of content analysed (501 scientific articles and 340 policy documents), this case does not tell us much about interactions between individuals or institutions, only how value frames have been communicated at the macro level. More specifically, it describes the types of values that are associated with the ecosystem concept in connection to individual, collective and policy frames as well as how these have changed over time. The link to the landscape is indirect and related to the ecosystem concept being commonly applied in landscape planning and management. On a conceptual and practical level, this allows for inferences about the impact on 
landscapes from science and policy frames.

\section{ii. Interactional Act}

The interactions are indirect and linked to how value frames change over time. Several interactions are assumed in this article, more precisely, policy frames are seen as collectively negotiated and influenced by both institutional frames (e.g. lobbying organisations) and individual frames (e.g. influential politicians) during the policymaking process. It is moreover assumed that academic literature characterise individual frames that have migrated into policy over time as the ecosystem concept is established (as a new scientific term) and vice versa (value frames moving from policy into science).

\section{iii. Framing Effects}

Scientific literature and policy documents are characterized by stable value frames that have not changed significantly over time, despite evolving challenges and public priorities (e.g. biodiversity crisis and climate change). Findings indicate that ecosystem research is often characterized by unstated value judgments and preferences, even though attempts are made by the scientific community to be objective. Clear value statements, on the other hand, characterize policy that is principally management-driven and human-centred. Six collective frames, with some internal frame variations, were defined: Humans first, Dual systems, Eco-science, Eco-holism, Animals first, Multicentric. Specific crises (e.g. climate change) and crossdisciplinary uptake (e.g. ecosystem services) have brought new value perspectives to the forefront of public discourse and triggered the modernisation of collective frames, representing a typology of 14 sub-frames. These frames have an impact on the landscape that depends on what aspect of the ecosystem concept scientists and policymakers prioritize, although this is an effect that can only be presumed. For instance, most policy documents and scientific publications centralise humankind. It is only in very rare cases that ecocentric or biocentric frames are applied, and certainly not in binding regulations that would have an actual impact on the landscape. In effect, system properties for land-use and management, as dominated by the anthropocentric "humans first" frame, would only change if there is an actual shift in how environmental policy frames landscapes.

\section{Crossing the Theoretical Divide}

The three case study articles deal with different topics (wetland restoration, stakeholder participation and the ecosystem concept) at different levels (ranging from micro to macro) and demonstrate the power of framing and its effects on the landscape, be it directly or indirectly. Interestingly, the cases reveal both horizontal and vertical framing effects. This can be illustrated using the implementation of new practices, such as the valuation of ecosystem services. This process would be subject to macro-level value frames in scientific literature and policy documents (e.g. guidelines and legislation). These would in turn be taken up at a meso level by institutions and individuals that impose their own frames on the implementation process, where, for example, project managers may perceive the new practice as a threat and try to minimise its impact. Subsequently, at a micro-level, individuals affected by the new practice would try to influence how things should be implemented within the contextual means provided, i.e. through participatory processes or negotiations. All of this corresponds to a chain of events where each level is influenced by new frames that are passed on to the next level. Ultimately, at the end of the chain, the entire framing process would affect how the landscape is managed, e.g. in terms of what ecosystem services are valued. The cases in this study illustrate the link between more abstract framing effects (value frames in science and policy) and how these are translated into actual impacts (individual frames in wetland restoration). Some of these effects will now be characterised according to the different functional categories introduced earlier (Table 2).

Table 2 supports the assumption that a single theoretical strand cannot cover the entire framing process and that frames need to be recognised as being both socially constructed and manifested through cognitive predispositions (the ontological and epistemological differences can in fact be seen as complimentary). The results also highlight that different aspects of the framing process are prioritised and interpreted differently depending on the theoretical approach taken. For example, the micro case is subject to cognitive factors that affect how wetlands are framed (e.g. values, beliefs and knowledge), while framing during the negotiation process was subject to social construction (e.g. power relations) and purpose-driven frames from the political administration (e.g. targets for a cleaner and more diverse agricultural landscape). All interact to generate an impact on the landscape that cannot be fully understood without an integrated multi-level approach. It is, of course, not possible for one study to explore all the distinct areas where frames have an impact (ranging from individual actors to policy-making); however, the aim has simply been to contextualise the case studies and to argue that an integrated approach improves our understanding of the framing process. This would preferably be coupled with a grounded approach to avoid theoretical tunnel vision Thomas \& James [48], Van Gorp [49].

\section{Discussion}

This paper has endeavoured to link framing processes to impacts in the real world, using the landscape concept to emphasize different framing effects. To achieve this objective, three case studies were presented (Section 4) to demonstrate framing effects at different levels of operationalization. The purpose of this was, in part, to show quantifiable impacts of framing at a micro level (on wetland restoration) as well as more intangible framing effects at a meso and macro level (relating to stakeholder participation and the ecosystem concept) as well as their relationship with direct or indirect impacts on the landscape. The innovative idea behind this multi-level approach was to distinguish, if not quantify, the cumulative impact of framing, and discuss an integrated approach to framing research. 
The intent was also to link the more abstract macro level (e.g. value frames in science and policy) to intermediate framing at a meso level (e.g. institutions affecting how policy is implemented) and framing effects on the ground (e.g. individual frames affecting wetland restoration). Aside to argue for an integrated approach, the principal motivation has been to facilitate a better understanding of the framing process.

There are, of course, some limitations to the method applied in this paper, and a certain degree of caution needs to be taken in drawing broader conclusions. For one, there is no link between the case studies, meaning that the framing effects demonstrated at the macro level cannot be linked with effects at the micro level. It would be nearly impossible to definitively argue that policy frames influence individual frames in specific ways. The range of factors that affect our heuristics (either as groups or individuals) is simply too complex and framing research is by its very nature qualitative and subject to subjectivities Donahue et al. [12], Van Gorp [49]. The case study analysis has also been somewhat superficial, principally, as the point of this investigation has not been to provide irrefutable evidence but to demonstrate how frames can be linked and operationalized in complex natural and social environments, and to argue that a multi-level synthesis of the framing process cannot be achieved without integrating different theoretical perspectives and levels. The breakdown of the framing process into three functional categories (cognitive, contextual and purpose-driven framing) was designed to allow integration and to disentangle it from theory (Table 2).

Table 2: Functional categories and framing affects across the case study articles.

\begin{tabular}{|c|c|c|c|}
\hline & Cognitive Frames* & Contextual Frames & Purpose-driven Frames \\
\hline \multirow[t]{2}{*}{$\begin{array}{l}\text { Micro case: } \\
\text { Wetland } \\
\text { restoration }\end{array}$} & $\begin{array}{l}\text { Educational and occupational factors } \\
\text { (knowledge-based) affect how individuals } \\
\text { frame wetlands (e.g., biodiversity was valued } \\
\text { differently based on educational background). }\end{array}$ & $\begin{array}{l}\text { Strategic one-on-one interactions } \\
\text { conducted by the negotiator were } \\
\text { key to convincing landowners } \\
\text { (e.g., engaging people in their } \\
\text { home environments facilitated } \\
\text { stakeholder "buy-in" into the } \\
\text { programmes). }\end{array}$ & $\begin{array}{l}\text { Specific narratives were employed by } \\
\text { the negotiator to persuade landowners } \\
\text { (e.g. case examples from a locally } \\
\text { engaged landowner and politician). }\end{array}$ \\
\hline & $\begin{array}{l}\text { Historical factors (experience and emotion- } \\
\text { based) influenced the environmental conditions } \\
\text { imposed on the restoration process (e.g. wanting } \\
\text { to restore landscape diversity or use the } \\
\text { wetlands as a water reservoir). }\end{array}$ & $\begin{array}{l}\text { Power-relationships affected } \\
\text { the negotiation process (e.g., } \\
\text { landowner participation } \\
\text { and interests from fishing } \\
\text { associations were prioritised over } \\
\text { environmental performance). }\end{array}$ & $\begin{array}{l}\text { Motivational factors introduced during } \\
\text { negotiations were based on stakeholder } \\
\text { interests (e.g. economic compensations } \\
\quad \text { and/or landscape restoration). }\end{array}$ \\
\hline \multirow[t]{2}{*}{$\begin{array}{l}\text { Meso case: } \\
\text { Stakeholder } \\
\text { participation }\end{array}$} & $\begin{array}{l}\text { Value-based predisposition towards } \\
\text { participation (related to perceived benefits) was } \\
\text { a key determinant for (or against) stakeholder } \\
\text { interactions (e.g., input from stakeholders was } \\
\text { only used when there was a positive belief in the } \\
\text { participatory process). }\end{array}$ & $\begin{array}{l}\text { Institutional lack of control and } \\
\text { support allowed managers to } \\
\text { design the participatory process in } \\
\text { accordance with their individual } \\
\text { framing (e.g. stakeholders were } \\
\text { involved at the end of the project } \\
\text { cycle, which made it impossible to } \\
\text { integrate other perspectives). }\end{array}$ & $\begin{array}{l}\text { Institutional framing of stakeholder } \\
\text { participation was principally geared } \\
\text { towards ensuring that project funding } \\
\text { was secured or maintained (e.g., } \\
\text { most organisations did not care how } \\
\text { participation was conducted, their only } \\
\text { interest being that it took place). }\end{array}$ \\
\hline & $\begin{array}{l}\text { Perception of power was a key determinant for } \\
\text { how stakeholders were engaged (e.g., managers } \\
\text { who thought that stakeholder participation } \\
\text { reduced their power would sometimes limit } \\
\text { stakeholder involvement). }\end{array}$ & \multicolumn{2}{|c|}{$\begin{array}{l}\text { Participatory approaches (reflecting both the context and purpose) were } \\
\text { based on underlying managerial intent (e.g. neither the institutional } \\
\text { framework nor policy on stakeholder participation prevented managers from } \\
\text { operationalizing individual value frames within their projects). }\end{array}$} \\
\hline \multirow[t]{2}{*}{$\begin{array}{l}\text { Macro case: } \\
\text { The } \\
\text { Ecosystem } \\
\text { Concept }\end{array}$} & $\begin{array}{l}\text { Science and policy definitions of the ecosystem } \\
\text { concept are normative in that they reflect } \\
\text { individual and collective values and preferences } \\
\text { (e.g. specific value assertions affect how } \\
\text { ecosystem services are conceptualised). }\end{array}$ & $\begin{array}{l}\text { Collaborative and/or negotiation } \\
\text { processes during policy making } \\
\text { and the scientific write-up process } \\
\text { are presumed to be influenced by } \\
\text { contextual factors (e.g. power- } \\
\text { relationships); however, the } \\
\text { macro case does not allow for any } \\
\text { inferences on this. }\end{array}$ & $\begin{array}{l}\text { Scientific literature and policy } \\
\text { documents convey stable value } \\
\text { structures (whether intentional } \\
\text { or unintentional) associated with } \\
\text { definitions of the ecosystem, } \\
\text { which affect how the concept is } \\
\text { operationalized in practice. }\end{array}$ \\
\hline & $\begin{array}{c}\text { Core frames associated with the ecosystem } \\
\text { concept are linked to specific value-systems } \\
\text { and are stable over time (e.g. anthropocentric } \\
\text { value frames dominate both scientific and policy } \\
\text { documents). }\end{array}$ & & $\begin{array}{l}\text { However, purpose-driven re-framing } \\
\text { implies changing sub-frames under } \\
\text { a given core frame (e.g. shifting an } \\
\text { individual's thinking to a different } \\
\text { system or cognition) that allows them } \\
\text { to reconfigure a concept using values } \\
\text { that fit their core frame }\end{array}$ \\
\hline
\end{tabular}


Cognitive factors were not the focus of the case studies, and, as such, only indirect effects underlying framing can be noted (e.g., knowledge-based factors affect the type of value assertions that were associated with landscapes).

The proposition made here is basically that we should take a more inductive approach to framing, to avoid focusing on only some theoretical explanations. Taking a Foucauldian approach to framing research, for example, the issue of power (e.g. operation, enactment and resistance to power) dominates many analytical approaches. This can be found in the literature on management and organisation, such as Entman [10,50], who focuses on the power of media in political systems, or, more recently Van Buren et al. [20], who focus on power relationships in the climate change debate. Power is naturally an important explanatory factor in this study as well. For instance, in the micro case, the negotiator successfully played with power dynamics by setting individuals at ease and making them feel in control during the negotiation process. This purpose-driven manipulation of power dynamics affected the environmental performance of the programmes negatively, while at the same time facilitating stakeholder "buy-in". This illustrates how power can affect the landscape directly and how it can be used as a tool. However, focusing on only power-relations would be to neglect how different value orientations and historical perspectives (e.g. some landowners remembered a more diverse landscape) dominated heuristics as well as the impact from the negotiators' communication skills and credibility when manipulating the framing process Brewer \& Gross [51], Buijs [36], Druckman [17]. The same arguments can be made for the meso case. In this instance, the project manager's position of power was a clear determinant in how participatory processes were designed. For instance, if a manager perceived that stakeholder participation threatened their sense of control (or power) they took steps to limit its influence, and managerial actions that were in accordance with the institutional frames were put in place. However, to focus only on power is to neglect different cultural perspectives (e.g. most projects were implemented in a multicultural setting) and perspectives on project management itself (e.g. most project managers came from a technocratic background) Buijs [36], George et al. [43].

For both case studies it is clear that power regimes is a strong explanatory variable at any level of analysis, whether individual or institutional, but it also obscures other explanations. As such, the inherent degree of complexity and dynamism in each case study lends support to two assumptions. First, that each framing process should be considered as temporally unique and context dependent Gillan [52] and, secondly, that framing research would benefit from being grounded and theory neutral Glaser \& Strauss [53], Strauss \& Corbin [54], Thomas \& James [48]. It also demonstrates the benefits of having separate case studies that can (empirically speaking) stand on their own, allowing for a balanced multi-level perspective and more realistic inferences to be made on framing effects at each distinct level. Results should essentially be considered equally valid even with differing philosophical assumptions as long as the methodological approach can be considered robust and valid.

To highlight the limitations imposed by theoretical tunnel vision, another example can be made from neo-institutional theory and the role of framing in an institutional setting. More specifically, how individuals (or agents) behave according to prevailing rules and norms George et al. [43] and the institution's role in stabilising power arrangements Schmidt [27] or establishing interactional patterns Fligstein \& McAdam [55]. On a basic level, institutional research allows for a link between macro-level structures (e.g. new organisational practices) and individual micro-level actions. The macro case portrays one aspect of this link, namely, the interactions between individuals and institutions in creating negotiated definitions of the ecosystem concept. This case study does not look into the interactions directly (e.g. real-time negotiations between actors) but rather the shared definitions put forward in scientific literature and policy documents as interpretive frames that extend beyond the documents themselves. Previous studies have shown that recurrent macro-level framing affects how individuals perceive and value ecosystems Barnaud \& Antona [56], Norgaard [57], with these frames affecting how people make decisions about the landscape once they are cognitively embedded. The uptake of the ecosystem services concept in natural sciences literature is an example of this, particularly in terms of the arguments made for the conservation of natural resources (e.g. biodiversity). Changes in meaning-making and framing are effectively changing how we value landscapes (e.g. becoming increasingly anthropocentric). To focus on the institutional setting is, however, to risk taking a top-down perspective that neglects the substantive actions taken by individuals (e.g. as illustrated by the behaviour of the project managers in the meso case). It may also cause the neglect of contextual elements that make each framing process unique (e.g. contextual factors that affected negotiations in the micro case).

The analytical approach was also adopted to stress the practical utility of integrated framing research. There are as such several findings that could be applied in practical terms. For example, results from the micro case could be used to develop the deliberative scope of environmental projects; findings from the meso case could be applied to improve the institutional uptake of new practices; and the macro case could be used to advance reframing techniques. In line with these suggestions, Lakoff [8] argues that there is an absence of specific frames in public (or popular) discourse, frames that would allow us to relate to landscapes in certain ways. We (as humans) most often separate ourselves from the landscape, a process that is deeply entrenched in most individual cognitive systems and very hard to change Buijs [36], Jerneck \& Olsson [26], Spangler [58]. This human-landscape perspective is consistent with early forms of anthropocentric framing that still dominates landscape (and 
project) management, scientific writing and policy-making. Taking inspiration from research on climate change framing e.g. Dewulf \& Bouwen [59], Stern [38], Van Buuren et al. [20], it is clear that we need to move away from this self-reinforcing system in which prevailing anthropocentric frames prevent us from alternative approaches to landscape management Norgaard [57].

\section{Conclusion}

Finally, the balance between discipline-based and integrated approaches to framing research cannot be resolved by this study. One problem is the difficulties associated with taking an integrated multi-level approach in contrast to the strengths and contributions of monodisciplinary research. Another practical problem is that, most often, academic research priorities (or funding agencies) remain focused on single-level approaches. This means that an integrated approach, despite its benefits, will require not only deep-level interdisciplinary, but also that different structures and procedures are promoted for these types of collaborative research efforts Holm et al. [60]. This would require that we acknowledge that a multi-level viewpoint could help framing research advance beyond its current pathdependent way of thinking, to mix complimentary perspectives of the same process that can improve our understanding.

\section{References}

1. Norton BG (2005) Values in Nature: A Pluralistic Approach. In Al Cohen \& W CH Contemporary Debates in Applied Ethics: Blackwell Publishers, USA.

2. Eder K (1996) The Social Construction of Nature: A Sociology of Ecological Enlightenment. SAGE publications, London, UK.

3. Harrison C, Davis G (2002) Conserving biodiversity that matters Journal of Environmental Management 65(1): 95-108.

4. Fischer A, Marshall K (2010) Framing the landscape: Discourses of woodland restoration and moorland management in Scotland. Journal of Rural Studies 26(2): 185-193.

5. Soini K, Aakkula J (2007) Framing the biodiversity of agricultural landscape: The essence of local conceptions and constructions. Land Use Policy 24(2): 311-321.

6. Howley P, Donoghue OC, Hynes S (2011) Exploring public preferences for traditional farming landscapes. Landscape and Urban Planning 104(1): 66-74.

7. Minsky M (1975) A framework for representing knowledge. In PH Winston, The psycology of computer vision, McGraw-Hill, New York, USA, pp. 211-277.

8. Lakoff G (2010) Why it matters how we frame the environment Environmental Communication 4(1): 70-81.

9. Bateson G (1954) A theory of play and fantasy. Psychiatric Research Reports 2: 39-51.

10. Entman RM (2007) Framing Bias: Media in the Distribution of Power. Journal of Communication 57(1): 163-173.

11. Goodman JR (2006) Beneficial or biohazard? How the media frame biosolids. Public Understanding of Science 15(3): 359-375.

12. Donahue WA, Rogan RG, Kaufman S (2011) Framing Matters Perspectives on Negotiation Research and Practice in Communication. Peter Lang, New York, USA.
13. Rein M, Schon DA (1996) Frame-critical policy analysis and framereflective policy practice. Knowledge and Policy 9(1): 85-104.

14. Chong D, Druckman JN (2007) Framing Theory. Annual Review of Political Science 10: 103-126.

15. Nelson TE, Oxley ZM, Clawson RA (1997) Towards a psychology of framing effects. Political Behavior, 19(3): 221-246.

16. Cornelissen JP, Werner MD (2014) Putting Framing in Perspective: A Review of Framing and Frame Analysis across the Management and Organizational Literature. The Academy of Management Annals 8(1): 181-235.

17. Druckman JN (2001) The Implications of Framing Effects for Citizen Competence. Political Behavior 23: 225-256.

18. Hanggli R, Kriesi H (2012) Frame Construction and Frame Promotion (Strategic Framing Choices). American Behavioral Scientist 56(3): 260-278.

19. Daviter F (2007) Policy Framing in the European Union. Journal of European Public Policy 14(4): 654-666.

20. Van Buuren A, Vink M, Warner J (2014) Constructing Authoritative Answers to a Latent Crisis? Strategies of Puzzling, Powering and Framing in Dutch Climate Adaptation Practices Compared. Journal of Comparative Policy Analysis: Research and Practice 18(1): 70-87.

21. Kahneman D, Tversky A (1984) Choices, Values, and Frames. American Psychologist 39(4): 341-350.

22. Shen F, Edwards HH (2005) Economic Individualism, Humanitarianism, and Welfare Reform: A Value-Based Account of Framing Effects. Journal of Communication 55(4): 795-809.

23. Gigerenzer G, Todd M (1999) Simple heuristics that make us smart. Oxford University Press, Newyork, USA.

24. Devignemont F, Singer T (2006) The empathic brain: how, when and why? Trends in Cognitive Sciences, 10(10): 435-441.

25. Snow DA, Rochford EB, Worden SK, Benford RD (1986) Frame Alignment Processes, Micromobilization, and Movement Participation. American Sociological Review 51: 464-481.

26. Jerneck A, Olsson L (2011) Breaking out of sustainability impasses: How to apply frame analysis, reframing and transition theory to global health challenges. Environmental innovation and societal transitions 1(2): 255-271.

27. Schmidt VA (2008) Discursive Institutionalism: The Explanatory Power of Ideas and Discourse. Annual Review of Political Science 11(1): 303-326.

28. Goffman E (1974) Frame Analysis - An Essay on the Organisation of Experience. Harper \& Row New York, USA.

29. Benford RD, Snow DA (2000) Framing processes and social movements: an overview and assessment. Annual Review of Sociology 26: 611-639.

30. Coninx I, Dewulf ARPJ, Steingrover EG, Walvd MF, Opdam P, et al. (2015) Framing ecosystem services: Affecting behaviour of actors in collaborative landscape planning? Land Use Policy 46: 223-231.

31. Van Hulst M, Yanow D (2014) From Policy "Frames" to "Framing": Theorizing a More Dynamic, Political Approach. The American Review of Public Administration 46(1): 92-112.

32. Dewulf A, Gray B, Putnam L, Lewicki R, Aarts N, et al. (2009) Disentangling approaches to framing in conflict and negotiation research: A meta-paradigmatic perspective. Human Relations 62(2): 155-193.

33. Matthes J (2012) Framing Politics: An integrative approach. American Behavioral Scientist 56(3): 247-259.

34. De Vreese CH (2012) New Avenues for Framing Research. American 
Behavioral Scientist 56(3): 365-375.

35. Kaltenborn BP, Bjerke T (2002) Associations between environmental value orientations and landscape preferences. Landscape and Urban Planning 59(1): 1-11.

36. Buijs AE, Elands BHM, Langers F (2009) No wilderness for immigrants: Cultural differences in images of nature and landscape preferences. Landscape and Urban Planning 91(3): 113-123.

37. Kaufman S, Gray B (2003) Using retrospective and prospective frame elicitation to evaluate environmental disputes. In L. Bingham \& R O'Leary, The Promise and Performance of Environmental Conflict Resolution. Washington DC Resources for the Future, USA.

38. Stern CP (2011) Contributions of Psychology to Limiting Climate Change. American Psychologist 66(4): 303-314.

39. Fuller BW (2009) Surprising cooperation despite apparently irreconcilable differences: Agricultural water use efficiency and CALFED. Environmental Science \& Policy 12(6): 663-673.

40. Schon DA, Rein M (1994) Frame reflection: toward the resolution of intractable policy controversies. Basic Books, New York, USA.

41. Van der Windt HJ, Swart JAA, Keulartz J (2007) Nature and landscape planning: Exploring the dynamics of valuation, the case of the Netherlands. Landscape and Urban Planning 79: 218-228.

42. Gross K, D Ambrosio L (2004) Framing Emotional Response. Political Psychology 25(1): 1-29.

43. George E, Chattopadhyay P, Sitkin SB, Barden J (2006) Cognitive Underpinnings of Institutional Persistence and Change: A Framing Perspective. The Academy of Management Review 31(2): 347-365.

44. Nickerson RS (1998) Confirmation bias: A ubiquitous phenomenon in many guises. Review of General Psychology 2(2): 175-220.

45. Jacoby WG (2000) Issue Framing and Public Opinion on Government Spending. American Journal of Political Science 44(4): 750-767.

46. Gross K (2008) Framing Persuasive Appeals: Episodic and Thematic Framing, Emotional Response, and Policy Opinion. Political Psychology 29(2): 169-192.

47. Tansley AG (1935) The Use and Abuse of Vegetational Concepts and Terms. Ecology 16: 284-307.

This work is licensed under Creative Commons Attribution 4.0 Licens
48. Thomas G, James D (2006) Reinventing grounded theory: some questions about theory, ground and discovery. British Educational Research Journal 32(6): 767-795.

49. Van Gorp B (2010) Strategies to take subjectivity out of framing analysis. In P D'Angelo \& JA Kuypers Doing news framing analysis: Empirical and theoretical perspectives Routledge, England, pp. 84-109.

50. Entman RM (2008) Media framing biases and political power: Explaining slant in news of Campaign 2008. Journalism 11(4): 389408.

51. Brewer RP, Gross K (2005) Values, Framing, and Citizens' Thoughts about Policy Issues: Effects on Content and Quantity. Political Psychology 26(6): 929-948.

52. Gillan K (2008) Understanding Meaning in Movements: A Hermeneutic Approach to Frames and Ideologies. Social Movement Studies 7(3): 247-263.

53. Glaser BG, Strauss A (1967) The Discovery of Grounded Theory: Strategies of Qualitative Research. New York: Aldine Transaction, New Brunswick, USA.

54. Strauss A, Corbin J (1990) Basics of Qualitative Research: Grounded Theory Procedures and Techniques. California: SAGE publications, Newbury Park, USA.

55. Fligstein N, McAdam D (2011) Toward a generak theory of strategic action fields. Sociological Theory 29(1): 1-26.

56. Barnaud C, Antona M (2014) Deconstructing ecosystem services: Uncertainties and controversies around a socially constructed concept. Geoforum 56: 113-123.

57. Norgaard RB (2010) Ecosystem services: From eye-opening metaphor to complexity blinder. Ecological Economics 69(6): 1219-1227.

58. Spangler B (2003) Beyond Intractability. Reframing Boulder, USA.

59. Dewulf A, Bouwen R (2012) Issue Framing in Conversations for Change: Discursive Interaction Strategies for "Doing Differences". The Journal of Applied Behavioral Science 48(2): 168-193.

60. Holm P, Goodsite ME, Cloetingh S, Agnoletti M, Moldan B (2013) Collaboration between the natural, social and human sciences in Global Change Research. Environmental Science \& Policy 28: 25-35.

\section{Your next submission with Juniper Publishers will reach you the below assets}

- Quality Editorial service

- Swift Peer Review

- Reprints availability

- E-prints Service

- Manuscript Podcast for convenient understanding

- Global attainment for your research

- Manuscript accessibility in different formats

( Pdf, E-pub, Full Text, Audio)

- Unceasing customer service

Track the below URL for one-step submission

https://juniperpublishers.com/online-submission.php 